\title{
Focus on male youths in addressing alcohol and drug abuse risk in the context of HIV prevention among young people
}

Population Council

Follow this and additional works at: https://knowledgecommons.popcouncil.org/departments_sbsr-rh

Part of the Demography, Population, and Ecology Commons, Family, Life Course, and Society Commons, International Public Health Commons, and the Substance Abuse and Addiction Commons How does access to this work benefit you? Let us know!

\section{Recommended Citation}

"Focus on male youths in addressing alcohol and drug abuse risk in the context of HIV prevention among young people," APHIA II Operations Research Project in Kenya OR Summary. Nairobi: Population Council, 2011. 


\section{Focus on male youths in addressing alcohol and drug abuse risk in the context of HIV prevention among young people}

Key Finding: Older male out-of-school youths in Kibera are more vulnerable to alcohol and drug abuse than any other group of young people

\section{Introduction}

Research evidence shows that people who abuse alcohol are more likely to engage in behaviour that puts them at risk of HIV infection, including having unprotected sex. Addressing alcohol and drug abuse is therefore imperative and should be a key priority in HIV prevention and management.

In 2010, APHIA II Operations Research Project collaborated with Support for Addictions Prevention and Treatment in Africa (SAPTA) Centre on research to identify factors associated with alcohol and drug use among out-of-school youth in Kibera, and to identify specific factors contributing to HIV risk, and to assess the impact of an intervention to link youths with an alcohol and drug abuse problem to counselling and rehabilitation services.

\section{The Intervention}

SAPTA used participatory educational theatre and Prevention Awareness Groups (PAGs) to disseminate alcohol and drug abuse reduction messages, and to encourage uptake of HIV counselling and testing. Youths found to be alcohol- and drug-dependent were offered enrolment in SAPTA's Outpatient Treatment Program.

\section{Key findings}

\section{Alcohol use:}

- Results show that male youth are more than twice as likely to report alcohol use and abuse as girls.

- Thirty-one per cent of the 15 to 19 year old males reported ever having used alcohol, compared to $14 \%$ of the girls.

- Fifty-one percent of the older males (20 to 24 years) had ever used alcohol compared to $21 \%$ girls in the same age group. However, recent drinking was not commonly reported among all groups of youths.

- Ten per cent of the older male youths were found to be risky or hazardous drinkers (8-14 drinks at one sitting) when the Alcohol Use Disorders Identification Test (AUDIT) was applied.

\section{Drug use:}

- Among older males (20-24 years), 23\% and $19 \%$ reported using 'miraa'/khat at baseline and endline respectively. Almost 15\% reported using bhang/marijuana in the past month.

- Among 15-19 year old males, 14\% and $16 \%$ reported having used 'miraa'/ khat in the previous month at baseline and endline respectively. Use of marijuana was reported by $7 \%$ and 
$13 \%$ at baseline and endline respectively.

- Use of either 'miraa'/khat or marijuana by the female youths was negligible.

- Using the Drug Abuse Screening Test (DAST-10), about $8 \%$ of the $15-19$ year old males and $5 \%$ of the older males could be classified as moderate drug users.

\section{Sexual behaviour:}

- Early marriage among girls is quite common, and nearly half of all girls aged $15-19$ years and about $75 \%$ of girls 20 to 24 years in the survey had ever been married, compared to less than a quarter of the older males. None of the boys in the younger agegroup had ever been married.

- Sexual activity is more common among girls: $64 \%$ of girls aged 15 to 19 years had sexual intercourse in the previous 12 months at both baseline and endline, compared to $27 \%$ and $40 \%$ of the boys in the same age group. Older female youth were also more likely to have had recent sex (86\%) than male youth in the same age group (70\%).

- Majority of the female youth had sex with regular partners. A small proportion of males in both age groups reported sex with non-regular partners.
- Reported condom use with last regular partner was highest among male youth, ranging from $59 \%$ in the 20-24 year old group, to $67 \%$ among 15-19 year olds at endline. The highest proportion reporting condom use with last regular partner among girls was $28 \%$ among the $15-19$ year olds at baseline.

- Condom use with a non-regular partner was high among the older males and females (20-24years), at 75\% among males and $58 \%$ among females at endline.

\section{Recommendations}

- In addressing alcohol and drug abuse among youths, programs need to focus on older male youths (20+years old), who were found to be the most vulnerable to alcohol and drug abuse.

- Interventions are also need to address alcohol and drug use by younger boys, whose use of marijuana and miraa/khat was found to be more common than alcohol.

- Youth-focused programs should consider integrating alcohol and drug education into their activities to mitigate their negative effects on risk behaviors as the youth grow older.

Source: Geibel S, J Okal et al. 2011. An assessment of alcohol and drug use among youth in Kibera. APHIA II OR Project Final Report. Population Council, Kenya

For more information, contact:

Harriet Birungi, Project Director, APHIA II OR Project in Kenya/Population Council, hbirungi@popcouncil.org, www.popcouncil.org (c) 2011 The Population Council, Inc. 